\title{
Notes on the vocalizations of Red-legged Thrush (Turdus plumbeus)
}

\section{Peter Boesman}

In the following we briefly analyze and compare voice of the different races of Red-legged Thrush (Turdus plumbeus). We also try to quantify the extent of any vocal differences using the criteria proposed by Tobias et al. (2010), as a support for taxonomic review.

We have made use of sound recordings available on-line from Xeno Canto (XC), Macaulay Library (ML), Avian Vocalizations Center (AVoCet) and The Internet Bird Collection (IBC).

An overview of song per race, illustrated with sonograms:
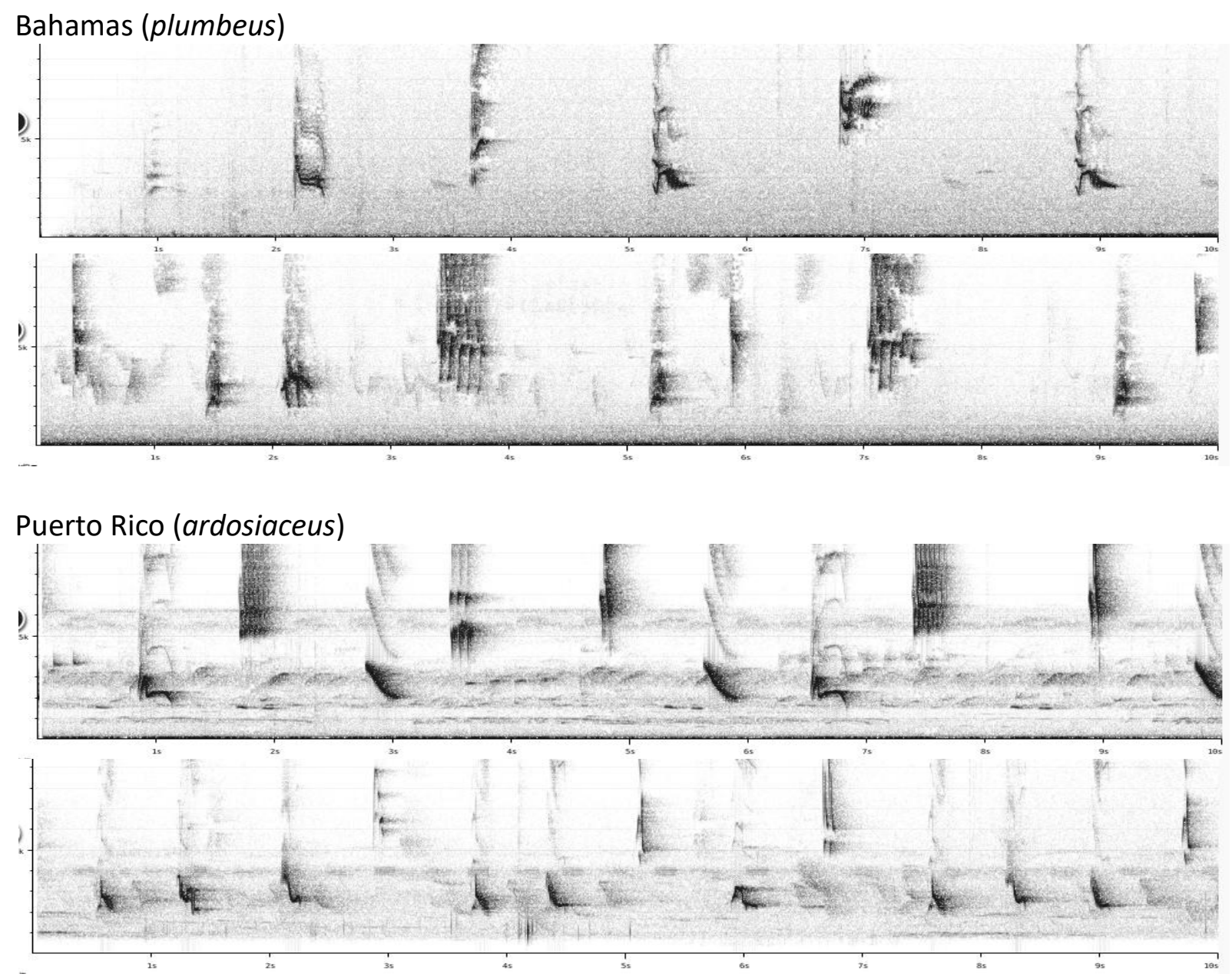

Dominican Republic (ardosiaceus)

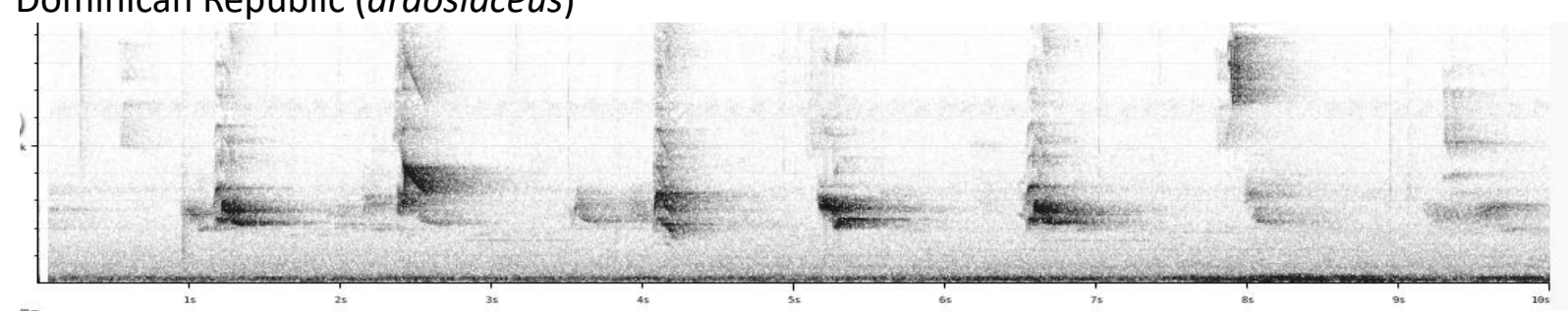




\section{HANDBOOK OF THE BIRDS PF/THE WORLD}

\section{ORNITHOLOGICAL NOTES}
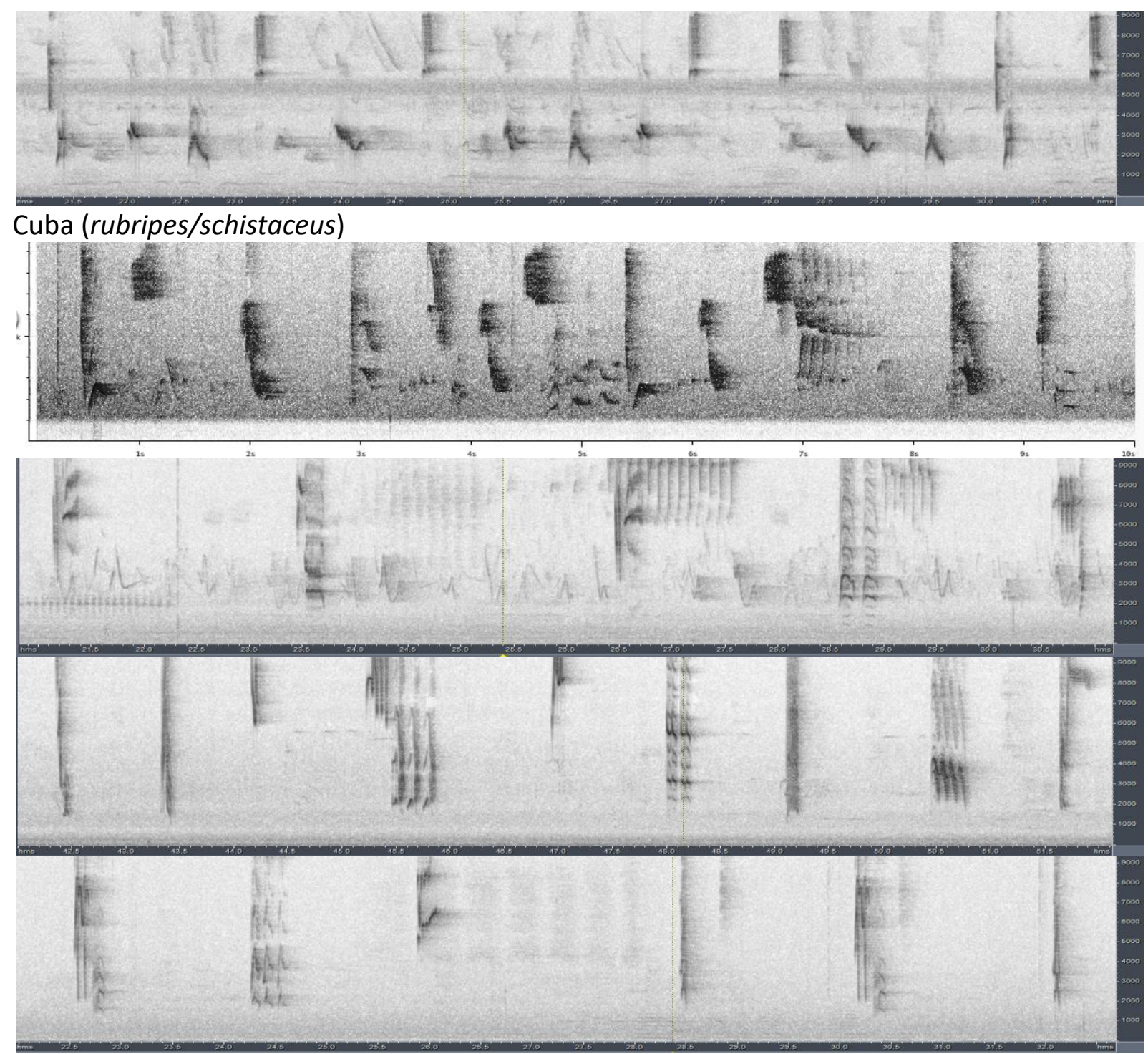

There are no recordings available of albiventris (Dominica).

There is a slight vocal difference between ardosiaceus (Hispaniola/Puerto Rico) and other races (Cuba/Bahamas):

ardosiaceus alternates 1-3 fairly melodious whistles at lower pitch with 1-2 high-pitched notes.

Other races have a similar alternating series of notes, but the lower-pitched notes are not at all melodious, rather squeaky (which can be seen from the large freq. range they cover, or loud harmonics or non-harmonic frequency bands). There is however some overlap, especially birds of Bahamas (plumbeus) are rather intermediate.

This could be given a vocal score of 1 (smaller freq. range of low-pitched notes and/or lack of loud harmonics for ardosiaceus).

A more thorough analysis would be required to find out if vocabulary of notes is distinct among races, but a larger set of recordings would be needed to perform such analysis. 
This note was finalized on 20th April 2016, using sound recordings available on-line at that moment. We would like to thank in particular the sound recordists who placed their recordings for this species on XC and $\mathrm{ML}$.

\section{References}

Tobias, J.A., Seddon, N., Spottiswoode, C.N., Pilgrim, J.D., Fishpool, L.D.C. \& Collar, N.J. (2010). Quantitative criteria for species delimitation. Ibis 152(4): 724-746.

\section{Recommended citation}

Boesman, P. (2016). Notes on the vocalizations of Red-legged Thrush (Turdus plumbeus). HBW Alive Ornithological Note 310. In: Handbook of the Birds of the World Alive. Lynx Edicions, Barcelona. (retrieved from http://www.hbw.com/node/1251827 on 15 October 2016). 